\title{
"CinNapht" dyes as new Cinnoline/Naphthalimide fused hybrids fluorophores: Synthesis, Photo-physical study and use for bio-imaging.
}

Minh-Duc Hoang, ${ }^{a} \ddagger$ Jean-Baptiste Bodin, ${ }^{b} \ddagger$ Farah Savina, ${ }^{b}$ Vincent Steinmetz, ${ }^{a}$ Jérôme Bignon, ${ }^{\text {a }}$ Philippe Durand, ${ }^{\text {a }}$ Gilles Clavier, ${ }^{\mathrm{c}}$ Rachel Méallet Renault ${ }^{\mathrm{b}}$ and Arnaud Chevalier*a

a. Université Paris-Saclay, CNRS, Institut de Chimie des Substances Naturelles, UPR 2301, 91198, Gif-sur-Yvette, France.

b. Université Paris-Saclay, CNRS, Institut des Sciences Moléculaires d'Orsay, Orsay, 91405, France.

c. Université Paris-Saclay, ENS Paris-Saclay, CNRS, PPSM, 91190, Gif-sur-Yvette, France.

\# These authors contributed equally to this work

† Footnotes relating to the title and/or authors should appear here.

Electronic Supplementary Information (ESI) available: [details of any supplementary information available should be included here]. See DOI: 10.1039/x0xx00000x

Six-membered diaza ring of Cinnoline have been fused on Naphthalimide dye to give donor-acceptor system called CinNapht. These red shifted fluorophore, that can be synthetised in gram scale, exhibits a large Stoke Shift and quantum yield up to 0.33 . It is also caracterized by strong solvatochromic effect for green to red emission as well and can be used for bioimaging

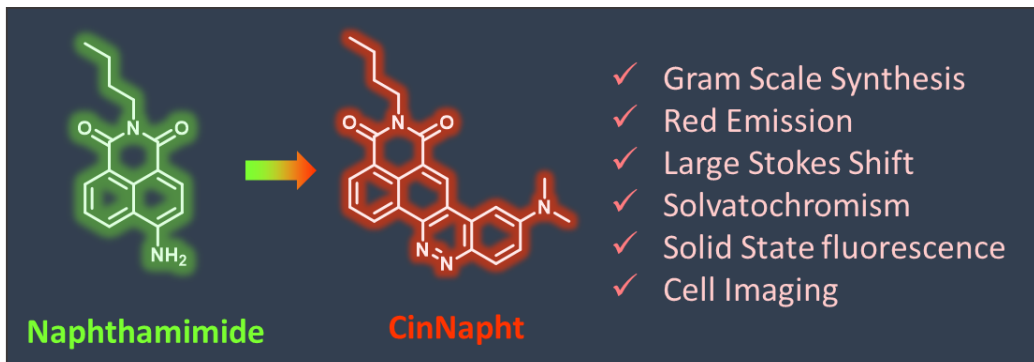

With the increasing interest of optical molecular imaging in medicine, fluorescence microscopy has seen constant development contributing to the emergence of new technologies and probes without discontinuity for nearly 40 years. Fluorogenic probes are now considered as critical tools for the study of biological environments. ${ }^{1}$ These sensors unmask brilliant fluorescence upon modification of their structure or of their environment, induced by multiple kind of biological stimuli. ${ }^{2}$ Therefore, there is definite interest in creating new chemical scaffold exhibiting fluorescent behavior that could later be used for the design of chemical fluorogenic probes. One of the most important and actual challenges is the synthesis of large Stokes shift red emitting fluorophores. ${ }^{3}$ Among the different families of fluorophores commonly used, the 1,8-naphthalimides such as 4-Amino-1,8-naphthalimide (ANI) exhibits a green emission combining good quantum yield and large Stokes Shift while possessing a particularly high chemical stability. ${ }^{4}$ 1,8-naphthalimides based sensors in solution or as part of material have been used for the detection of multiple analytes such as anions, metals or enzymes, highlighting their interest for fluorescence imaging. ${ }^{5}$ The easy functionalization of their imide nitrogen atom enables fine tuning of the fluorophore properties such as solubility or organelle targeting. ${ }^{6}$ However, their uses in imaging experiments are limited to the green region of the spectrum. To overcome this drawback, some groups have focused on the synthesis of $\pi$-extended naphthalimides fluorophores such as styrylnaphthalimides. ${ }^{7}$ The latter were found very promising red to NIR emitting dyes and were used for designing fluorogenic probes. ${ }^{8}$ Other examples including a fused pyranone, furan or carbazole rings $^{9}$ have also been reported but with less interesting photophysical properties. Nonetheless this strategy seems promising for there are many examples of red shifted fused hybrids fluorohores. ${ }^{10}$ We describe in this paper the synthesis of fused ring Cinnoline/Naphthalimide hybrid here called CinNapht dye. Cinnolines are aromatic heterocycles incorporating an azobenzene moiety that usually do not fluoresce, mainly because of nonradiative deactivation through photoisomerization of the azo bond. ${ }^{11}$

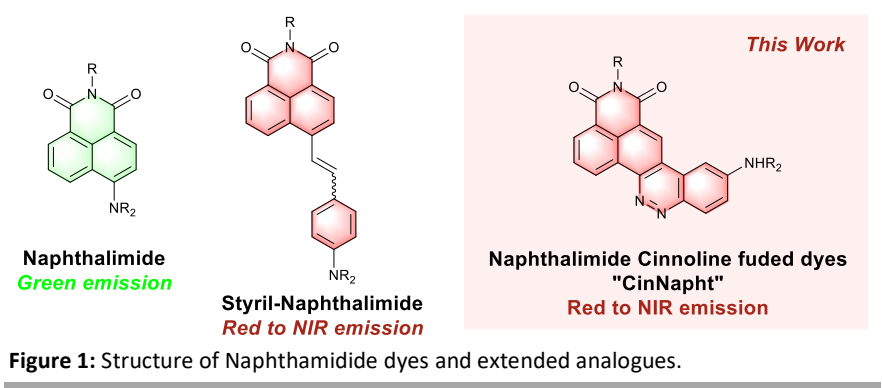


These molecules can nevertheless be turned into fluorescent structures by constraining the conformation of the $\mathrm{N}=\mathrm{N}$ double bond like it is in cinnoline scaffold. ${ }^{12}$ A significant number of fluorophores have recently been described incorporating this scaffold. Nevertheless many of these examples have required quaternization of the nitrogen atom to generate a Push-Pull electron effect, and induce an intramolecular charge transfer (ICT) necessary for fluorescence emission. ${ }^{13}$ More recently, fluorogenic probes in which a cinnoline is an integral part of a push-pull backbone have been developed. In these cases the azo bond is formed in situ following nitric oxide mediated nitrosation of an aniline precursor according to the "covalentassembly" principle, firstly proposed by Anslyn in $2010^{14}$ and then exemplified for multiple times. ${ }^{15}$ To the best of our knowledge, only one of these probes is formed with a molecular skeleton incorporating a naphthalimide like dye. ${ }^{15 a}$ However, no description of its photophysical properties is given. Moreover, it was not isolated and such strategy is limited to the NO detection. We will show in this article that this type of molecule can nevertheless possess original photophysical properties that deserve to be highlighted. We first proceeded with the synthesis of these fused naphthalimide cinnoline hybrid.

4-amino-1,8-naphthalic anhydride 1 (Scheme 1) was first synthesized from commercial 4-bromo analog by a two steps process involving an aromatic nucleophilic substitution with sodium azide followed by reduction under Staudinger conditions (cf. Supplementary Material). This aniline was then brominated in ortho position using $\mathrm{N}$-bromosuccinimide in hexafluoroisopropanol (HFIP) ${ }^{16}$ to provide the intermediate 2 with $92 \%$ yield, and the naphthalimide 3 was formed by reaction with $n$-butylamine in the yield of $92 \%$. It should be mentioned that no purification was needed for both of these two steps which greatly facilitates the synthetic process. The biaryl $\mathbf{4}$ was then obtained by Suzuki coupling of $\mathbf{3}$ with 3(Dimethylamino)phenylboronic acid in the yield of $82 \%$. Under the diazotization conditions, $\mathrm{NaNO}_{2}$ /dilute $\mathrm{HCl}, 4$ was converted in a mixture of two regioisomers resulting either from an azo coupling reaction in para position (5a) or in ortho position (5b) in a $84: 16$ ratio (determined by HPLC analysis of the crude mixture, Figure S1).
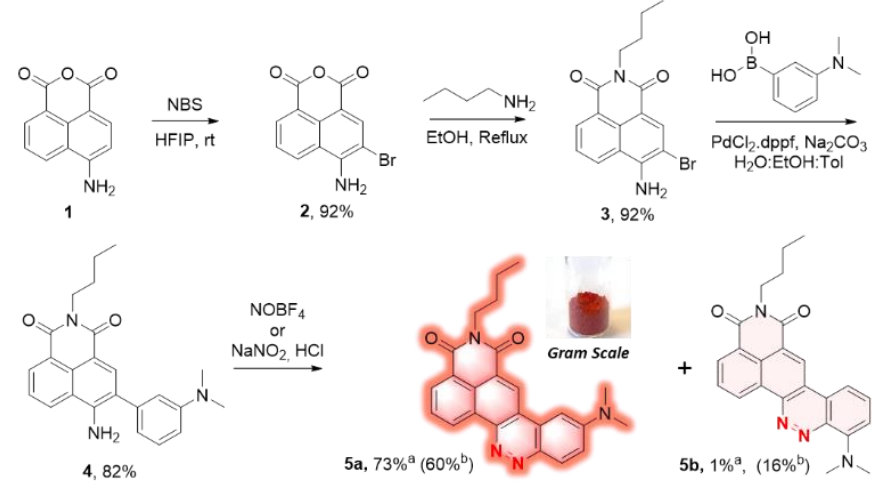

\section{\%}

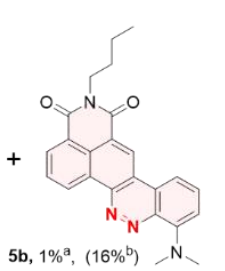

Scheme 1: Synthesis of CinNapht $\mathbf{5 a}$ end $\mathbf{5 b}$. alsolated yield using $\mathrm{NOBF}_{4}$ blsolated yield using $\mathrm{NaNO}_{2} / \mathrm{HCl}$

The predominant CinNapht 5 a was obtained with only $58 \%$ yield after a purification. The minor compound $\mathbf{5 b}$ was obtained in the yield of $16 \%$ and exhibited a weak fluorescence emission that we decided not investigate further. By contrast, CinNapht 5a was found to be much more emissive. In order to optimize its synthesis, azo coupling reaction of $\mathbf{4}$ was attempted with $\mathrm{NOBF}_{4}$ as diazotization reagent in $\mathrm{CH}_{3} \mathrm{CN}$. It turned out that this method enabled the almost exclusive formation of the compound 5a. HPLC analysis showed $96: 4$ ratio in favor of CinNapht 5a (Figure S2) which could be isolated after purification in the yield of $73 \%$ with a high purity of $98.5 \%$ (Figure S3). The complete synthetic pathway was also reproduced with success in large scale in order to demonstrate its viability for gram scale synthesis of the CinNapht dyes.

Table 1: Photophysical properties of CinNapht 5a

\begin{tabular}{|c|c|c|c|c|c|c|c|c|}
\hline Entry & Solvent & $E_{T}(30)^{a}$ & $\begin{array}{c}\lambda_{\max } \mathrm{Abs}^{\mathrm{b}} \\
(\mathrm{nm})\end{array}$ & $\begin{array}{c}\varepsilon \max \\
\left(\mathrm{M}^{-1} \cdot \mathrm{cm}^{-1}\right)\end{array}$ & $\begin{array}{c}\lambda_{\max } \mathrm{Em} \\
(\mathrm{nm})\end{array}$ & $\begin{array}{l}\text { Stokes Shift } \\
\qquad\left(\mathrm{cm}^{-1}\right)\end{array}$ & $Q Y^{c}$ & $\begin{array}{c}\text { Life Time } \\
\text { (ns) }\end{array}$ \\
\hline 1 & Hexane & 31 & 469 & 12200 & 520 & 2091 & 0.01 & 0.37 \\
\hline 2 & Toluene & 33,9 & 480 & 12000 & 550 & 2652 & 0.09 & 0.88 \\
\hline 3 & Dioxane & 36 & 477 & 21000 & 572 & 3482 & 0.16 & 1.89 \\
\hline 4 & $\mathrm{CHCl}_{3}$ & 39,1 & 489 & 15700 & 566 & 2782 & 0.25 & 2.23 \\
\hline 5 & DCM & 40,7 & 488 & 16400 & 591 & 3571 & 0.33 & 3.67 \\
\hline 6 & DMSO & 45,1 & 496 & 15500 & 682 & 5499 & 0.06 & 1.26 \\
\hline 7 & $\mathrm{EtOH}$ & 51,9 & 493 & 15200 & 667 & 5291 & 0.05 & 0.84 \\
\hline 8 & $\mathrm{MeOH}$ & 55,4 & 492 & 15100 & 681 & 5640 & 0.02 & 0.47 \\
\hline 9 & In Cell & n.a. & 475 & n.a. & 590 & 4104 & n.d. & n.d. \\
\hline 10 & Solid & n.a. & 491 & n.a. & 581 & 3446 & n.d. & n.d. \\
\hline
\end{tabular}

apolarity coefficient of solvents based on literature ${ }^{17}$ bValues corresponding to $\mathrm{S}_{0}-\mathrm{S}_{1}$ transition but strong $\mathrm{S}_{0}-\mathrm{S}_{2}$ transition is also observed (see Supporting Information Fig $\mathrm{S} 5$ to S12) ${ }^{b}$ Relative $\mathrm{QY}$ determined at $25^{\circ} \mathrm{C}$ using $\left[\mathrm{Ru}(\mathrm{bpy})_{3}\right] \mathrm{Cl}_{2}(\mathrm{QY}=0.04 \text { in air Saturated } \mathrm{H} 2 \mathrm{O})^{18}$

We then performed a complete analysis of the photophysical properties of CinNapht $\mathbf{5 a}$ in different solvents. Absorption, excitation and emission spectra were recorded, molar extinction coefficient $(\varepsilon)$ (Figure S4), fluorescence quantum yields and fluorescence life times (Figure S5) were measured (Cf Table 1). All spectra and data are presented in Supporting Information (Figures S6 to S13). The first observation is a significant red shift in the emission wavelength relative to the initial naphthalimide fluorophores. Thus an $89 \mathrm{~nm}$ batochromic shift of the $\lambda_{\max } \mathrm{Em}$ was observed between ANI ( $\lambda_{\max } E m=502$ $\mathrm{nm}$ ) and CinNapht $5 \mathrm{a}\left(\lambda_{\max } \mathrm{Em}=591 \mathrm{~nm}\right)$ in $\mathrm{CH}_{2} \mathrm{Cl}_{2}$ (Cf Figure S14). Fluorescence quantum yields were found to be mostly modest in all tested solvents with nevertheless values up to 0.33 in DCM and a $16400 \mathrm{~cm}^{-1}$ Stokes Shift which is quite satisfying. ${ }^{19}$ 
Another important characteristic of this fluorophore is the possibility of exciting it at higher energy on the $\mathrm{SO} \rightarrow \mathrm{S} 2$ transition band (Figure S15). This allows to significantly enlarge the difference between the absorption and emission maxima, which then reaches values exceeding $10000 \mathrm{~cm}^{-1}$. Finally, we also noted a solid-state fluorescence of $\mathbf{5 a}$ that was measured using a XENIUS SAFAS fluorimeter and a solid-sate sample holder and revealed an orange-red emission centered at $581 \mathrm{~nm}$ (Figure S16). As the push-pull structure of the compound suggested an ICT type fluorescence, a solvatochromic study was carried out. By lighting at $365 \mathrm{~nm}$ solutions of CinNapht 5a in different solvents a color panel ranging from green to red-pink was obtained, likely correlated with the solvent polarity (Figure 2a). This was confirmed by the linear relationship between the $\lambda_{\max } \mathrm{Em}$ of CinNapht $\mathbf{5 a}$ and the polarity coefficient $\mathrm{E}_{\mathrm{T}}(30)$ of the solvents with an exception for DMSO, (figure S17). This partial lack of adequacy could be explained by the fact that the Dimroth and Reichardt method does not integrate any basicity parameter, which is particularly high in the case of DMSO.

In order to confirm this, the solvent effect was also analyzed with the methodology developed by Catalán ${ }^{20}$ that relies on the description of the solute-solvent interactions with four independent parameters: polarizability (SP), dipolarity (SdP), acidity (SA) and basicity (SB).

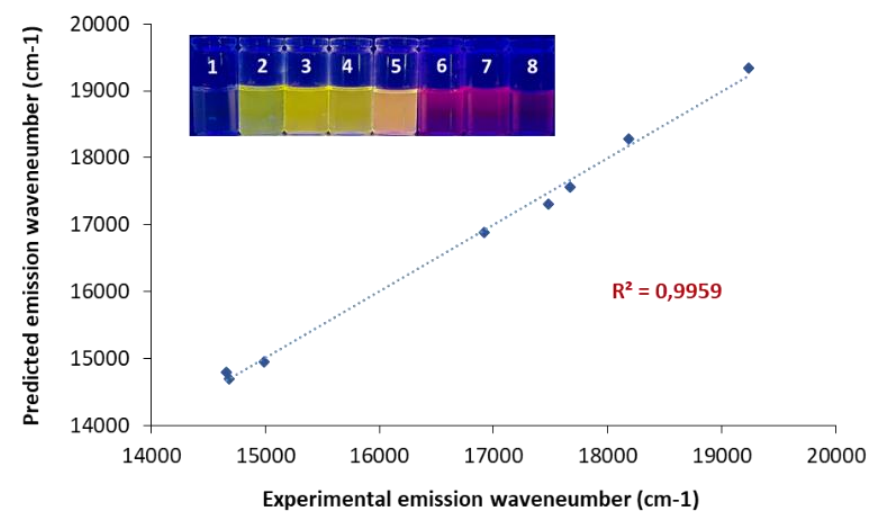

Figure 2: Solvatochromism Study: Visual representation of CinNapht solution under $365 \mathrm{~nm}$ light. (1. Hexane, 2. Toluene, 3. $\mathrm{CHCl}_{3}$, 4. Dioxane, 5. DCM, 6. EtOH,
7. MeOH, 8. DMSO) and Plot of experimental and predicted emission wavenumber (Catalan method)

The solvent-dependent maximum emission wavenumber $(\bar{v})$ is formulated in equation (1) as:

$$
\bar{v}=\bar{v}_{0}+a \times S P+b \times S d P+c \times S A+d \times S B
$$

where $\bar{v}_{0}$ is the value of the property in the gas phase, and the coefficients $a-d$ are the regression coefficients describing the sensitivity of the wavenumber to the different solute-solvent interactions. The fit of the experimental fluorescence wavenumbers in the various solvent gives:

$$
\begin{array}{r}
\bar{v}=19950( \pm 54)-725( \pm 40) S P-2503( \pm 24) S d P \\
-1506( \pm 3) S A-3012( \pm 67) S B
\end{array}
$$

showing that the fluorescence of CinNapht is mainly dependent on dipolarity, acidity and basicity parameters (See complete values Figure S18). Equation (2) together with the linear correlation between calculated $\bar{v}$ and experimental $\bar{v}$ (Graph, Figure 2) confirmed the solvatochromic behavior of the CinNapht 5a which is in accordance with its push-pull structure suggesting that ICT is responsible for the emission. To complete the experimental study and rationalize the photophysical properties, (TD)DFT calculations were carried out. The geometry of the CinNapht dye is flat and the first transition $(\mathrm{SO} \rightarrow \mathrm{S} 1)$ happens from the HOMO to the LUMO

The HOMO is centred on the amino-cinnoline part while the LUMO is more localized on the naphthalimide part of the dye. This result together with the representation of the density difference confirm the intramolecular charge transfer (ICT) nature of the first excited state (Figure S19). The possibility of a twisted induced charge transfer (TICT) excited state was also evaluated but the energy level of that state is higher than the ICT one $(E(S 1-T I C T)>E(S 1-I C T))$ even when solvent effect was included.
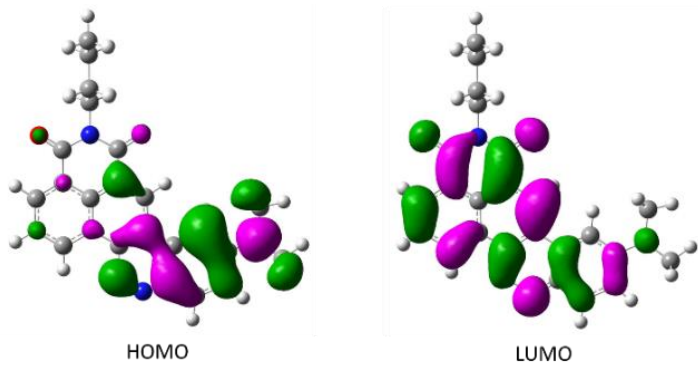

Figure 3: Isocontour plot of the $\mathrm{HO}$ and LU molecular orbitals (isovalue 0.004)

The solvatochromic effect observed in the fluorescence spectra is thus coming from solvent effects and not from the transition from a locally excited state to a TICT one.

Finally, we have validated the potential of these new fluorophores in cell imaging experiments. CinNapht $\mathbf{5 a}$ was incubated at $5 \mu \mathrm{M}$ with living A549 cells.

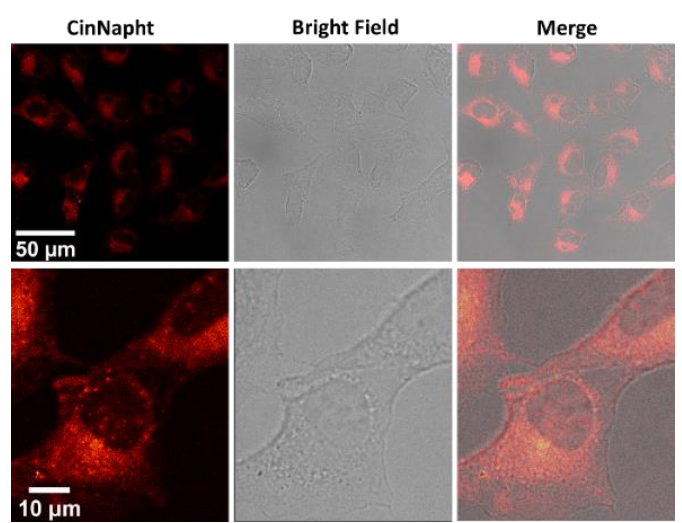

Figure 4: Confocal microscopic images of A549 lung cancer cells treated with CinNapht 5a $(5 \mu \mathrm{M})$

The images presented Figure $\mathbf{3}$ demonstrate the viability of our fluorophores for cell imaging. No pretreatment was necessary to enable cell penetration thereby strengthening the potential of CinNapht for fluorescence microscopy. Emission and excitation spectra were recorded in cell during microscopy experiments (Figure S20) and revealed that CinNapht 5a exhibits a Stokes Shift large enough to enable an excitation at $475 \mathrm{~nm}$ (Maximum of excitation measured in cell) while recording fluorescence across the full range of emitting fluorescence from 500 to $700 \mathrm{~nm}$ centered at $591 \mathrm{~nm}$. We emphasis that at the concentration used for these cell imaging experiments, fluorophore 5a showed no toxicity (see Figure S21). Complete cytotoxicity study was carried out and did not 
reveal any significant toxicity even at high concentration (50 $\mu \mathrm{M})$.

To conclude, we describe here a new fluorophore based on fused Naphthalimide Cinnoline hybrid structure so called CinNapht. This fluorophore shows promising fluorescence properties combining a red emission and a large stokes shift. Calculations have confirmed an ICT-like behavior characteristic of a push-pull structure that is clearly identified in the skeleton of the CinNaphth's. This characteristic is reflected in the photophysical properties by a strong solvatochromism effect. This non-toxic molecule can be used for in cellulo imaging experiments. We believe that an optimization of the structure of CinNaphth's should allow a significant improvement of the photophysical properties of these fluorophores, thus making them promising tools for cell imaging.

\section{Conflicts of interest}

There are no conflicts to declare.

\section{Acknowledgments}

This project has received funding by the French National Research Agency under the program CHARMMMAT ANR-11-LABX-0039-grant. We thank Romain Lebars and Sandrine Lecart from Imagerie Gif light facility for their kind help in microscopy experiments. This work was granted access to HPC resources from the "Mésocentre" computing center of CentraleSupélec and École Normale Supérieure ParisSaclay supported by CNRS and Région île-de-France (http://mesocentre.centralesupelec.fr/). We thanks Univ. ParisSaclay NanoPE platform at DER Chimie, Ecole Normale Supérieure Paris-Saclay for using Xenius SAFAS fluorimeter. We thanks the Région lle-de-France and DIM NanoK for financial support. The University Paris-Saclay and the CNRS are acknowledged for funding.

\section{Notes and references}

¥ These authors contributed equally to this work.

1. a) J. Zhou and H. Ma, Chem. Sci., 2016, 7, 6309-6315; b) J. V. Jun, D. M. Chenoweth and E. J. Petersson, Org. Biomol. Chem., 2020, 18, 5747-5763; c) X. Tian, L. C. Murfin, L. Wu, S. E. Lewis and T. D. James, Chem. Sci., 2021, DOI: 10.1039/d0sc06928k.

2. a) J. Chan, S. C. Dodani and C. J. Chang, Nat. Chem., 2012, 4, 973984; b) Y. Fu and N. S. Finney, RSC Adv., 2018, 8, 29051-29061; c) J. B. Grimm, L. M. Heckman and L. D. Lavis, Prog. Mol. Biol. Transl. Sci., 2013, 113, 1-34; d) S. Singha, Y. W. Jun, S. Sarkar and K. H. Ahn, Acc. Chem. Res., 2019, 52, 2571-2581.

3. a) C. S. Abeywickrama, K. J. Wijesinghe, R. V. Stahelin and Y. Pang, Chem. Commun., 2017, 53, 5886-5889; b) X. Ren, F. Zhang, H. Luo, L. Liao, X. Song and W. Chen, Chem. Commun., 2020, 56, 2159-2162; c) M. Mas-Montoya, M. F. Montenegro, A. Espinosa Ferao, A. Tarraga, J. N. Rodriguez-Lopez and D. Curiel, Org. Lett., 2020, 22, 3356-3360.

4. L. Wang, M. Fujii, M. Yamaji and H. Okamoto, Photochem. Photobiol. Sci., 2018, 17, 1319-1328.

5. a) R. M. Duke, E. B. Veale, F. M. Pfeffer, P. E. Kruger and T. Gunnlaugsson, Chem. Soc. Rev., 2010, 39, 3936-3953; b) H.-Q. Dong, T.-B. Wei, X.-Q. Ma, Q.-Y. Yang, Y.-F. Zhang, Y.-J. Sun, B.-B. Shi, H. Yao, Y.-M. Zhang and Q. Lin, J. Mater. Chem. C, 2020, 8, 13501-13529; c) X. Jia, Y. Yang, Y. Xu and X. Qian, Pure Appl.
Chem., 2014, 86, 1237-1246; d) L. Zhou, L. Xie, C. Liu and Y. Xiao, Chin. Chem. Lett, 2019, 30, 1799-1808.

6. a) L. Zhang, F. Su, X. Kong, F. Lee, S. Sher, K. Day, Y. Tian and D. R. Meldrum, ChemBioChem, 2016, 17, 1719-1724; b) S. I. Reja, M. Gupta, N. Gupta, V. Bhalla, P. Ohri, G. Kaur and M. Kumar, Chem. Commun., 2017, 53, 3701-3704.

7. a) P. A. Panchenko, A. N. Arkhipova, O. A. Fedorova, Y. V. Fedorov, M. A. Zakharko, D. E. Arkhipov and G. Jonusauskas, Phys. Chem. Chem. Phys., 2017, 19, 1244-1256; b) A. N. Arkhipova, P. A. Panchenko, Y. V. Fedorov and O. A. Fedorova, Mendeleev Commun., 2017, 27, 53-55.

8. a) X. Zheng, W. Zhu, D. Liu, H. Ai, Y. Huang and Z. Lu, ACS Appl. Mater. Interfaces, 2014, 6, 7996-8000; b) J.-W. Chen, C.-M. Chen and C.-C. Chang, Org. Biomol. Chem., 2017, 15, 7936-7943; c) J. Lee, S. A. Yoon, J. Chun, C. Kang and M. H. Lee, Anal. Chim. Acta., 2019, 1080, 153-161; d) M. Ye, W. Hu, M. He, C. Li, S. Zhai, Z. Liu, Y. Wang, H. Zhang and C. Li, Chem. Commun., 2020, 56, 62336236.

9. a) R. Umeda, H. Nishida, M. Otono and Y. Nishiyama, Tetrahedron Lett., 2011, 52, 5494-5496; b) M. Havlik, V. Talianova, R. Kaplanek, T. Briza, B. Dolensky, J. Kralova, P. Martasek and V. Kral, Chem. Commun., 2019, 55, 2696-2699.

10. a) A. Y. Bochkov, I. O. Akchurin, O. A. Dyachenko and V. F. Traven, Chem. Commun., 2013, 49, 11653-11655; b) S. Kothavale, A. G. Jadhav and N. Sekar, Dyes and Pig., 2017, 137, 329-341; c) A. Chevalier, P.-Y. Renard and A. Romieu, Chem. Eur. J., 2014, 20, 8330-8337; d) M. J. H. Ong, R. Srinivasan, A. Romieu and J.-A. Richard, Org. Lett., 2016, 18, 5122-5125.

11. a) A. Chevalier, P.-Y. Renard and A. Romieu, Chem. Asian J., 2017, 12, 2008-2028; b) H. M. D. Bandara and S. C. Burdette, Chem. Soc. Rev., 2012, 41, 1809-1825.

12. J. A. Stikeleather, Chem. Phys. Lett., 1973, 21, 326-329.

13. a) Y. Shen, Z. Shang, Y. Yang, S. Zhu, X. Qian, P. Shi, J. Zheng and Y. Yang, J. Org. Chem., 2015, 80, 5906-5911; b) J. Jayakumar, G. Vedarethinam, H. C. Hsiao, S. Y. Sun and S. C. Chuang, Angew. Chem. Int. Ed., 2020, 59, 689-694.

14. Y. Yang, S. K. Seidlits, M. M. Adams, V. M. Lynch, C. E. Schmidt, E. V. Anslyn and J. B. Shear, J. Am. Chem. Soc, 2010, 132, 1311413116.

15. a) X. Zhu, J. Q. Chen, C. Ma, X. Liu, X. P. Cao and H. Zhang, Analyst, 2017, 142, 4623-4628; b) X. Lv, Y. Wang, S. Zhang, Y. Liu, J. Zhang and W. Guo, Chem. Commun., 2014, 50, 7499-7502; c) C. Li, W. J. Tang, W. Feng, C. Liu and Q. H. Song, Anal Chim Acta, 2020, 1096, 148-158; d) C. G. Dai, J. L. Wang, Y. L. Fu, H. P. Zhou and Q. H. Song, Anal. Chem., 2017, 89, 10511-10519; e) Y. Shen, Q. Zhang, X. Qian and Y. Yang, Anal. Chem., 2015, 87, 1274-1280; f) P. R. Escamilla, Y. Shen, Q. Zhang, D. S. Hernandez, C. J. Howard, X. Qian, D. Y. Filonov, A. V. Kinev, J. B. Shear, E. V. Anslyn and Y. Yang, Chem. Sci., 2020, 11, 1394-1403.

16. R.-J. Tang, T. Milcent and B. Crousse, J. Org. Chem., 2018, 83, 930938.

17. C. Reichardt, Chem. Rev., 1994, 94, 2319-2358.

18. K. Suzuki, A. Kobayashi, S. Kaneko, K. Takehira, T. Yoshihara, H. Ishida, Y. Shiina, S. Oishi and S. Tobita, Phys. Chem. Chem. Phys., 2009, 11, 9850-9860.

19. a) J. Valanciunaite, E. Kempf, H. Seki, D. I. Danylchuk, N. Peyrieras, Y. Niko and A. S. Klymchenko, Anal. Chem., 2020, 92, 6512-6520; b) J. A. Gonzalez-Vera, F. Fueyo-Gonzalez, I. Alkorta, M. Peyressatre, M. C. Morris and R. Herranz, Chem. Commun., 2016, 52, 9652-9655; c) P. Jana, A. Siva, V. Soppina and S. Kanvah, Org. Biomol. Chem., 2020, 18, 5608-5616; d) A. H. Ashoka, P. Ashokkumar, Y. P. Kovtun and A. S. Klymchenko, J. Phys. Chem. Lett., 2019, 10, 2414-2421.

20. J. Catalan, J. Phys. Chem. B, 2009, 113, 5951-5960. 